\title{
Use of Peer Mentoring, Interdisciplinary Collaboration, and Archival Datasets for Engaging Undergraduates in Publishable Research
}

\author{
Jonathan J. Hammersley*, Micheal L. Waters and Kristy M. Keefe \\ Department of Psychology, Western Illinois University, Macomb, IL, United States
}

Keywords: undergraduate research, clinical psychology, archival data, collaboration, liberal arts college, state university, Interdisciplinary

We agree wholeheartedly with Dr. Sharon Brehm, the 2007 President of the American Psychological Association, who stated: "I believe that undergraduate research is one of the three most valuable experiences that colleges and universities can offer their undergraduate students (Keynote Address, 24th Annual Mid-America Undergraduate Psychology Research Conference)." We would add that engaging in undergraduate research can be enjoyable and rewarding, for students as well

OPEN ACCESS

Edited by:

Jeanine Lee McHugh Skorinko, Worcester Polytechnic Institute,

United States

Reviewed by:

Gary Leo Dunbar:

Central Michigan University,

United States

${ }^{*}$ Correspondence:

Jonathan J. Hammersley jjh135@wiu.edu

Specialty section

This article was submitted to

Educational Psychology,

a section of the journal

Frontiers in Psychology

Received: 03 December 2018

Accepted: 14 January 2019

Published: 06 February 2019

Citation:

Hammersley JJ, Waters ML and Keefe KM (2019) Use of Peer

Mentoring, Interdisciplinary

Collaboration, and Archival Datasets

for Engaging Undergraduates in

Publishable Research.

Front. Psychol. 10:96

doi: 10.3389/fpsyg.2019.00096 as their faculty mentors. There is nothing quite like observing students becoming interested and engaged in research, planning and carrying their own projects, getting excited to analyze their data, and then experiencing the pride of presenting or publishing their project. This is perhaps one of the best aspects of being a psychology faculty member.

Teaching at large state universities, or at small liberal arts colleges, comes with certain challenges for conducting research with undergraduates. Other authors have addressed models for involving undergraduates in high-quality research and encouraging presentation and publication of findings(e.g., Gibson et al., 1996; Hughes, 2014; McKelvie and Standing, 2018). A plethora of research literature also addresses challenges of improving writing (Stellmack et al., 2012; Jorgensen and Marek, 2013; Greenberg, 2015) and statistical skills (e.g., Lyle and Crawford, 2011; Lim et al., 2015; Hartnett, 2016); or for a truly novel approach to teaching statistics, see Irving (2015). Other practices, such as fostering interest in quality research during introductory psychology courses, are also beyond the scope of our article.

Our article focuses on challenges inherent in engaging undergraduate students in high quality, publishable research at underfunded colleges and universities, which often have fewer resources dedicated to conducting research (lack of time, participants, equipment, and other support) and whose faculty have high teaching loads and service commitments. We also focus on the difficulties of researching certain topics and describe some potential solutions that could include collaborative efforts and utilization of archival data.

\section{CHALLENGES}

\section{Engaging Students}

Engaging undergraduates in publishable research projects is challenging. Despite many clear benefits to both students and faculty (Landrum and Nelsen, 2002; Hughes, 2014; Woodzicka et al., 2015), a relatively low percentage of students take advantage of opportunities to conduct research. In the National Survey of Student Engagement through the Center for Postsecondary Research at Indiana University (National Survey of Student Engagement, 2018), only 21\% of college seniors at public universities and $25 \%$ at private universities reported engaging in research with faculty. 
This number varies across institutions, such as Research I universities (26\%), schools with fewer than 2,500 total students (30\%), and with Arts \& Sciences focus (44\%), perhaps partly due to different definitions of research activities. Certain students (non-traditional seniors age 25+, 14\%; first generation college students, 20\%) report less involvement in research.

Thus, fostering student interest in faculty research programs is a significant challenge.

We have advertised research studies and the potential for undergraduate involvement within and outside of the department. Student abstracts from conference presentations are also displayed prominently within the department, so students are aware of research achievements of other students. Our labs have been fortunate in that the topics that we study seem to stimulate student interest and involvement: suicidality, depressive and anxiety symptoms, attentional deficits, traumatic experiences, mental health treatments, and drug use, for example.

\section{Clinical Research}

Clinical and counseling psychology graduate program admissions are popular aspirations for undergraduates, and as the largest subspecialties in psychology, faculty can expect students to inquire about gaining experience researching clinical topics (Norcross et al., 2014). Further, students with aspirations for doctoral study in clinical or counseling psychology Ph.D. programs can expect requirements to include laboratory courses and research experience, strong letters of recommendations, and well-crafted personal statements, as well as high GPA and GRE scores (Norcross and Sayette, 2014).

However, it can also be very challenging to establish a clinical research program, especially at universities without access to psychiatric clients, that are not attached to teaching hospitals or clinics. Below we offer several further recommendations for establishing interesting research programs that can involve students.

\section{RECOMMENDATIONS}

\section{Peer Mentoring}

Clinical research and other interesting subtopics can be beneficial for recruiting student researchers potentially interested in becoming involved in publishable research. We just concluded a project on caffeine and nicotine use that involved many undergraduates and is likely to result in publications, and we recently began a multi-institutional collaborative project examining video game imagery, that has seemed popular among undergraduates looking for research experience.

One way we achieve undergraduate involvement is through the use of vertical peer supervision within labs, in which graduate students or more advanced undergraduate students can help supervise and mentor small teams of undergraduates. Undergraduates may relate to and feel less intimidated by fellow students, and may feel more comfortable asking questions or discussing mistakes or become more engaged in the research when noticing the enthusiasm of graduate students.

\section{Forming Research Collaborations}

There are a number of advantages of interdisciplinary research collaboration as well as a few potential drawbacks. For example, interdisciplinary research teams tend to produce research that receives more citations and is thus influential (Wuchty et al., 2007). Scientific research, especially certain STEM and medical fields, appears to have become more collaborative in recent decades (Wuchty et al., 2007; Burroughs, 2017). Interdisciplinary collaboration can be complicated, and there may be risks involved, especially for early career, tenure-track faculty (Rhoten and Andrew, 2004; Moore et al., 2018); however, complex problems such as poverty, violence, and human behaviors or social issues may be best approached by diverse interdisciplinary research teams who bring a broad range of skills and knowledge (Gehlert et al., 2014; Graesser et al., 2018). Collaborative research can result in synergy (Katz and Martin, 1997) as well as increased creativity, motivation, and deeper, more nuanced understanding for students (Woodzicka et al., 2015). Interdisciplinary problembased learning, a collaborative group learning process, developed to prompt students in health professions to learn beyond rote memory and to develop critical thinking, problem-solving, and research skills, which are associated with enhanced cognitive outcomes as well as student satisfaction, engagement, and perceived usefulness (Davidson and Major, 2014).

Moreover, as a result of the Job Outlook 2018 survey, (National Association of Colleges Employers, 2017) recently found that the popular skills that current employers now value included abilities in problem-solving $(82.9 \%)$, work in a team (82.9\%), written communication (80.3\%), leadership (72.6\%), analytical/quantitative areas (67.5\%), and verbal communication (67.5\%). Some faculty (Szostak, 2007; Everett, 2016) have suggested that these findings may speak to the importance of interdisciplinary training and research, to assist students in developing such skills.

In our experiences, collaborating across institutions and disciplines is an effective way to pool funds and resources such as equipment, supplies, and research assistants. For example, successful completion of interdisciplinary projects in collaboration with biology and chemistry departments, which allowed faculty and students from these disciplines to work together and learn about new areas of science and research from one another, demonstrate the potential of such arrangements. One project involving health effects of consuming alkalized watered, which was carried out between the psychology and chemistry departments at a small liberal arts college, allowed faculty and students to work together across disciplines and learn about one another's respective disciplines and research methodology. Several students were able to use the project for senior seminar capstone projects and presented the results on campus.

In another project carried out in a collaboration between psychology and biology departments at Western Illinois University, we are examining neurotransmitter genotypes related to addictive behaviors, from DNA obtained from saliva. Portions of this project have been presented both on campus and at major psychological conferences, and are also currently being written 
up for publication by faculty and students. Our labs have also collaborated on several occasions with other labs within the university and at other state universities to pool efforts and resources, resulting in a number of conference presentations and manuscript submissions. Between 5 and 10 students each year from 2014 through 2018 were also able to obtain excellent research experience and training from these endeavors.

Although interdisciplinary writing and research groups have been utilized at the graduate postgraduate levels (Cuthbert et al., 2009), a relative dearth of research literature exists on interdisciplinary research teams in undergraduate psychology. Models do exist for interdisciplinary integration of undergraduate psychology coursework at both liberal arts and Research I institutions (Golding and Kraemer, 2000; Ebersole and Kelty-Stephen, 2017), which might help students and faculty across departments appreciate and value concepts and scientific methods from other disciplines. Other faculty have also created courses with interdisciplinary assignments and teaching techniques (Ross et al., 2013) or "cluster courses" that revolve around an interdisciplinary topic (Wingert et al., 2014).

Burroughs (2017) recommends utilizing the expertise of librarians to help set up collaborative relationships, or searching for departments and individuals on campus who have shown a propensity for collaborative research. At Western Illinois University, our Center for Innovation in Teaching and Research has a searchable database of faculty research topics which can also be used to set up potential collaborations (http://www.wiu.edu/ CITR/services/research.php).

\section{Archival Data}

Another way in which we have successfully developed research programs that incorporate students is to utilize archival, or publicly available, databases to examine clinical topics. A primary benefit of accessing and analyzing archival data has been the study of topics that otherwise would not be possible (or would be very difficult) outside of medical schools or Research I universities.

In addition to studying clinical topics, especially behaviors with relatively low base rates (e.g., suicidality, inhalant abuse) or treatment outcomes that would otherwise take years to complete, additional benefits of archival data analysis might include the study of behaviors and epidemiology in large, nationally representative samples across genders, sexual orientation, or socioeconomics, that also allow for the use of statistics that require large sample sizes (e.g., structural equation modeling, moderation, and mediation analysis). In our lab, we have benefited from learning and refining new statistical approaches. Some behaviors we have been able to study would also have been difficult for a small college Institutional Review Board to review and approve.

While there can be many benefits to using archival data, several possible drawbacks also exist. For example, available archival data is often several years to decades old, and data collected through surveys often (though not always) preclude experimental designs and require correlational analyses. The available data from surveys or clinical ratings may not be a direct measurement of a behavior. Moreover, the datasets are often very complicated and can take weeks or months to clean and organize. Two archival datasets we have utilized for research projects (American College Health Association, 2009; Center for Collegiate Mental Health, 2015) required a lengthy application and review process, similar to a grant or journal submission. We have also used data from the SAHMSA Treatment Episodes Dataset (Substance Abuse Mental Health Services Administration, 2005), the Carolina Abecedarian Project (ABC; Campbell and Ramey, 2010), and mandated, publicly reported crime statistics on university websites for clinically relevant projects. Other colleagues have used Amazon's Mechanical Turk (MTurk; http://www.mturk.com; reviewed by Shapiro et al., 2013), the Institute for Social Research (https:// www.icpsr.umich.edu/icpsrweb/), the Henry Murray Archive (https://murray.harvard.edu/), or the Midlife Development in the U.S. Study (MIDUS; http://midus.wisc.edu/) and have collected data through Reddit, Facebook, or other social media. Psi Chi has also been moving toward crowdsourcing and data sharing.

\section{CONCLUSION}

We strongly encourage engaging undergraduates in faculty research programs, so that both students and faculty can experience the satisfaction and enjoyment that result from this collaboration. However, involving undergraduate students in quality research projects, especially clinical research that involves examining psychopathology or addiction, can be quite challenging. Strategically implementing procedures that include vertical peer mentoring, collaborating with colleagues across department/disciplines or institutions, and utilizing available archival databases can help faculty from all subdisciplines overcome some of the challenges. All in all, such procedures can be useful and allow for interesting and rewarding experiences while increasing the likelihood of publishable undergraduate research.

\section{AUTHOR CONTRIBUTIONS}

JJH developed the initial concept for the article, wrote the initial draft and revisions and was the primary author. MLW contributed to drafts of the article, reviewed and provided critical revisions, and created the reference list. KMK helped develop the initial concepts for the article and provided critical revisions. All authors approved the paper for submission.

\section{FUNDING}

Funding from a WIU University Research Council grant made possible some of the research discussed in this article.

\section{ACKNOWLEDGMENTS}

Thank you also to Dr. Eugene Mathes for discussions and mentoring which led to ideas for this article. 


\section{REFERENCES}

American College Health Association (2009). American College Health Association-National College Health Assessment, fall 2008-spring 2009 [Data file]. Baltimore, MD: American College Health Association.

Burroughs, J. M. (2017). No uniform culture: patterns of collaborative research in the humanities. Portal: Libraries and the Academy. Johns Hopkins University Press, 507-527. doi: 10.1353/pla.2017.0032

Campbell, F. A., and Ramey, C. T. (2010). "Carolina abecedarian project," in Childhood Programs and Practices in the First Decade of Life: A Human Capital Integration, eds A. J. Reynolds, A. J.Rolnick, M. M. Englund, and J. A. Temple (Cambridge, UK: Cambridge University Press), 76-98.

Center for Collegiate Mental Health (2015). 2014 Annual Report. Publication No. STA 15-30.

Cuthbert, D. M., Spark, C. H., and Burke, E. K. (2009). Disciplining writing: the case for multi-disciplinary writing groups to support writing for publication by higher degree by research candidates in the humanities, arts and social sciences. High. Educ. Res. Dev. 28, 137-149. doi: 10.1080/07294360902725025

Davidson, N., and Major, C. H. (2014). Boundary crossings: cooperative learning, collaborative learning, and problem-based learning. J. Excellence Coll. Teach. $25,7-55$. Available online at: http://celt.muohio.edu/ject/issue.php? $v=25 \& n=3$ $\% 20$ and $\% 204$

Ebersole, T. M., and Kelty-Stephen, D. G. (2017). Psychology as an evolving, interdisciplinary science: integrating science in sensation and perception from fourier to fluid dynamics. Psychol. Learn. Teach. 16, 115-124. doi: $10.1177 / 1475725716681266$

Everett, M. (2016). Interdisciplinary studies: a site for bridging the skills divide. J. Effect. Teach. 16, 20-31. Available online at: https://uncw.edu/jet/articles/ Vol16_2/Everett.html

Gehlert, S., Hall, K., Vogel, A., Hohl, S., Hartman, S., Nebeling, L., Thornquist, M. (2014). Advancing transdisciplinary research: the transdisciplinary research on energetics and cancer initiative. J. Transl. Med. Epidemiol. 2, 1-9. Available online at: http://europepmc.org/abstract/MED/25356437

Gibson, P. R., Kahn, A. S., and Mathie, V. A. (1996). Undergraduate research groups: Two models. Teach. Psych. 23, 36-37. doi: $10.1207 /$ s15328023top2301 7

Golding, J. M., and Kraemer, P. J. (2000). Integrating psychology into a multidisciplinary-multicultural undergraduate program at a research I university. Teach. Psychol. 27, 169-173. doi: 10.1207/S15328023TOP2703_02

Graesser, A. C., Fiore, S. M., Greiff, S., Andrews-Todd, J., Foltz, P. W., and Hesse, F. W. (2018). Advancing the science of collaborative problem solving. Psychol. Sci. Public Interest 19, 59-92. doi: 10.1177/1529100618808244

Greenberg, K. P. (2015). Rubric use in formative assessment: a detailed behavioral rubric helps students improve their scientific writing skills. Teach. Psychol. 42, 211-217. doi: $10.1177 / 0098628315587618$

Hartnett, J. L. (2016). Using data mining to teach applied statistics and correlation. Teach. Psychol. 43,142-146. doi: 10.1177/0098628316636292

Hughes, J. L. (2014). A model for a research program that encourages undergraduate students to present and publish original research. Psi Chi J. Psychol. Res. 19, 220-24. doi: 10.24839/2164-8204.JN19.4.220

Irving, L. T. (2015). Teaching statistics using dance and movement. Front. Psychol. 6:50. doi: 10.3389/fpsyg.2015.00050

Jorgensen, T. D., and Marek, P. (2013). Workshops increase students' proficiency at identifying general and APA-style writing errors. Teach. Psychol. 40, 294-299. doi: $10.1177 / 0098628313501037$

Katz, J. S., and Martin, B. R. (1997). What is research collaboration? Res. Policy 26, 1-18. doi: 10.1016/S0048-7333(96)00917-1

Landrum, R. E., and Nelsen, L. R. (2002). The undergraduate research assistantship: an analysis of the benefits. Teach. Psychol. 29, 15-19. doi: 10.1207/S15328023TOP2901_04

Lim, S. W., Ng, G. J., and Wong, G. Q. H. (2015). Learning psychological research and statistical concepts using retrieval-based practice. Front. Psychol. 6:1484. doi: $10.3389 /$ fpsyg. 2015.01484
Lyle, K. B., and Crawford, N. A. (2011). Retrieving essential material at the end of lectures improves performance on statistics exams. Teach. Psychol. 38, 94-97. doi: $10.1177 / 0098628311401587$

McKelvie, S., and Standing, L. G. (2018). Teaching psychology research methodology across the curriculum to promote undergraduate publication: an eight-course structure and two helpful practices. Front. Psychol. 9:2295. doi: 10.3389/fpsyg. 2018.02295

Moore, M., Martinson, M. L., Paula, S., Nurius, P. L., and Kemp, S. P. (2018). Transdisciplinarity in research: perspectives of early career faculty. Res. Social Work Pract. 28, 254-264. doi: 10.1177/1049731517708033

National Association of Colleges and Employers (2017). The Key Attributes Employers Seek on Students' Resumes [Press release]. Available online at: www. naceweb.org/about-us/press/class-2015-skills-qualities-employers-want.aspx

National Survey of Student Engagement (2018). Engagement Insights: Survey Findings on the Quality of Undergraduate Education - Annual Results 2018. Bloomington, IN: Indiana University Center for Postsecondary Research.

Norcross, J. C., and Sayette, M. A. (2014). Insider's Guide to Graduate Programs in Clinical and Counseling Psychology. New York, NY: Guilford.

Norcross, J. C., Sayette, M. A., Stratigis, K. Y., and Zimmerman, B. E. (2014). Of course: prerequisite courses for admission into APA-accredited clinical and counseling psychology programs. Teach. Psychol. 41, 360-364. doi: $10.1177 / 0098628314549713$

Rhoten, D., and Andrew, P. (2004) Risks and rewards of an interdisciplinary research path. Science 306:2046. doi: 10.1126/science.1103628

Ross, K., Hooten, M. A., and Cohen, G. (2013). Promoting science literacy through an interdisciplinary approach. Bioscene 39, 20-26.

Shapiro, D. N., Chandler, J., and Mueller, P. A. (2013). Using mechanical turk to study clinical populations. Clin. Psychol. Sci. 1, 213-220. doi: $10.1177 / 2167702612469015$

Stellmack, M. A., Keenan, N. K., Sandidge, R. R., Sippl, A. L., Konheim-Kalkstein, Y. L. (2012). Review, revise, and resubmit: The effects of self-critique, peer review, and instructor feedback on student writing. Teach. Psychol. 39, 235-244. doi: $10.1177 / 0098628312456589$

Substance Abuse and Mental Health Services Administration, Office of Applied Studies (2005). Treatment Episode Data Set (TEDS): Discharges from Substance Abuse Treatment Services. Rockville, MD.

Szostak, R. (2007). How and why to teach interdisciplinary research practice. J. Res. Pract. 3, 1-16. Available online at: http://jrp.icaap.org/index.php/jrp/article/ view/92/89

Wingert, J. R., Wasileski, S. A., Peterson, K., Mathews, L. G., Lanou, A. J., and Clarke, D. (2014). The impact of integrated student experiences on learning. J. Scholarsh. Teach. Learn. 14:42. doi: 10.14434/josotl.v14i1.3938

Woodzicka, J. A., Ford, T. E., Caudill, A., and Ohanmamooreni, A. (2015). A Successful Model of Collaborative Undergraduate Research: A Multi-Faculty, Multi-Project, Multi-Institution Team Approach. Teach. Psych. 42, 60-63. doi: $10.1177 / 0098628314549711$

Wuchty, S., Jones, B. F., and Uzzi, B. (2007). The increasing dominance of teams in production of knowledge. Science 5:1036. doi: 10.1126/science.11 36099

Conflict of Interest Statement: The authors declare that the research was conducted in the absence of any commercial or financial relationships that could be construed as a potential conflict of interest.

Copyright (๑) 2019 Hammersley, Waters and Keefe. This is an open-access article distributed under the terms of the Creative Commons Attribution License (CC BY). The use, distribution or reproduction in other forums is permitted, provided the original author(s) and the copyright owner(s) are credited and that the original publication in this journal is cited, in accordance with accepted academic practice. No use, distribution or reproduction is permitted which does not comply with these terms. 